\title{
El sacerdote en un mundo en transformación
}

Al P. Lope Cilleruelo, que supo serio.

¿En qué sentido hablamos hoy del mundo en transformación? Siempre lo ha estado, pero se dan épocas o períodos históricos, en los que el cambio se hace más acelerado. El final de la crisis lo ignoramos y por eso los pesimistas temen que la amenaza destructora que ensombrece nuestro futuro, cuando los hombres son capaces de provocar la ruina total o casi total de la humanidad, se convierta en una realidad desoladora. Los optimistas, en cambio, esperan porvenir de paz, de progreso y de fraternidad humana universal, que aleje definitivamente las guerras, el hambre y las injusticias sociales.

Ambas perspectivas provocan una expectación bifronte, cargada de temor y desesperanza una, de ilusión y felicidad la otra. El talante de cada uno condiciona su actitud, pero lo ineludible para todos es vivir en un presente problemático, esperando no sabemos qué, en situación de tránsito, de caminantes, de inestabilidad momentánea. Este es el pathos radical de nuestra existencia insegura, con el cual hemos de contar y que el sacerdote no puede olvidar, al estar en el mundo como enviado de Dios para comunicar a los hombres el mensaje de salvación.

Toma actualidad lo que san Pablo escribia a los corintios: "Lo que afirmo es que el plazo se ha acortado; en adelante, los que tienen mujer pórtense como si no la tuvieran los que sufren, como si no sufrieran; los que gozan como si no gozaran; los que adquieren, como si no poseyeran; los que sacan partido de este mundo, como si no disfrutaran, porque el papel de este mundo está para terminar" ${ }^{1}$. San Pablo ignoraba la inminencia del fin y también nosotros lo desconocemos, pero su advertencia es válida, pues los sentimientos de aquellos primeros cristianos debieron ser semejantes a los nuestros.

1. 2 Cor 7. 29-31. 
La consecuencia de esta situación radical en nuestra disposición afectiva es la inestabilidad. No sólo una inestabilidad propia de nuestra precariedad, ya que todos sabemos que, por ser mortales, caminamos hacia la muerte. Esto lo sabemos, pero como decía Madaule: "sé que he de morir, pero no lo creo". Se trata de una forma de actualización, de una intensificación del riesgo, de un sentir que todo se hace inseguro en el ámbito de que normalmente consideramos todavía como perspectiva de nuestra existencia. Es curioso observar cómo ha disminuido nuestra atención al hecho de la muerte. Este tema, tan presente en nuestros clásicos, constituía una meditación ineludible de los ejercicios espirituales. Se hablaba de la muerte describiendo con todo lujo de detalles los últimos momentos, el viático, la extrema-unción, la pérdida de fuerzas, el agotamiento final. Hoy nada de esto ocupa un puesto en nuestras prédicas, tal vez, por una tendencia inconsciente ante un hecho más inesperado y presente que antaño. Hablar de la muerte en un tiempo de estabilidad social, como era la España de los siglos XVI y XVII era necesario para conmover a gentes bien instaladas en un mundo capaz de prever un futuro inconmovible para varias generaciones. Hoy, en cambio, ios padres ignoran lo que será de sus hijos y aún su propio futuro está lleno de interrogantes nada halagadores.

La inestabilidad priva de la seguridad, ese sentimiento imprescindible para equilibrar la vida. Por falta de seguridad, la juventud desprecia el pasado, en el que no encuentra garantía; por falta de seguridad se entrega al presente, para gozar cuanto puede, no sea que le arrebaten lo único que está a su alcance; por inseguridad, no se preocupa demasiado de un futuro, que se siente impotente para construir, por falta de bases firmes, sobre qué aposentarlo. "Cuando en su biografía quiso Stefan Zweig calificar lo que ha sido su mundo, "El mundo de ayer", encuentra una expresión afortunada. Le llama, con nostalgia de desterrado, "El mundo de la seguridad". Y una vez terminada su autobiografía se suicida, como buen vienés descreído, abriendo el grifo del gas del alumbrado. Porque el mundo en el que ahora tiene que vivir ya no es el mundo de la seguridad" ".

Desde entonces acá los fundamentos del equilibrio han ido debilitándose en proceso acelerado y creciente. Rof Carballo encuentra en el crecimiento de la inseguridad la razón de la agresividad humana y animal, es decir, de la violencia. Los animales se tornan fieros cuando se sienten amenazados, cuando su seguridad entra en

2. R. CARBALLO, El hombre a prueba (Madrid 1951) 165. 
crisis. Lo mismo le acontece al hombre: "Nunca sabremos bien, dice, hasta qué punto nuestras ideas van' misteriosamente nutridas por el 'espiritu de los tiempos'. Dejó de ser el mundo seguro; a la fuerza se vio obligado el hombre a renunciar como ideal de su vida al pensamiento de que algún día podría descansar tranquilo, refugiado en la seguridad de sus rentas, de sus tierras, de su pensión de jubilado o, por lo menos, en la seguridad de su patria: El porvenir se volvió terriblemente incierto para todos. ¿Podemos considerar una casualidad que, en este mismo momento, la biología dé un insensible cambio de frente $\mathrm{y}$, de pronto, descubra que no todo el organismo es seguridad, afán de equilibrio, sino todo lo contrario, agresividad pura, tensión de ataque, creación constante, actividad, vigilia?"?

¿Contra quién se despertará la agresividad sino contra quienes encarnan la amenaza? Contra toda forma de autoridad, la politica, la familiar, la moral. El fenómeno contestatario y rebelde se ha hecho universal. En los llamados "países libres" se mira al comunismo como portador de la "liberación". En los comunistas la rebeldia anhela la libertad que disfrutan los otros. En la familia, las normas de convivencia, a poco exigentes que sean, irritan a los hijos. En la moral, se peca muchas veces simplemente por no someterse a lo mandado. El desbordamiento de la inmoralidad sexual es, en gran parte, una forma de agresividad contra cualquier forma de censura o prohibición que provenga de la sociedad o de la Iglesia. Sin percatarse de ello, porque en gran parte obedece a un proceso inconsciente, se pasa de la rebeldía concreta a leyes y normas a la que calificaba Camus de rebeldia "metafísica", a la negación de Dios, por ver en él la fuente de la autoridad y de la ley. Es la reacción del hombre acosado, del hombre enloquecido en la desesperanza, que busca a ciegas y a lo loco lo que, con su actitud, está haciendo más difícil de alcanzar: La tranquilidad, no sólo externa, sino de su propia alma, de su conciencia, de su calidad de ser creado y subordinado".

En esta misma línea se halla Alvin Toffler: "En primer lugar, escribe, me ha parecido muy claro que el choc del futuro no representa hoy una amenaza de poder para un lejano porvenir, sino una enfermedad real que afecta ya a un número de personas creciente sin cesar; este espacio psico-biológico se puede describir en términos médicos y psiquiátricos como el mal del cambio... Si se arranca a un individuo de su cultura de origen para insertarle bruscamente

3. R. CARBallo, El hombre a prueba, 168.

4. Cf. A. CAMUS, L'homme révolté (Paris 1951) 39-41. 
en un cuadro completamente diferente del suyo, en el cual deberá regular su comportamiento sobre un sistema completo de referencias - una forma distinta de concebir el tiempo, el espacio, el trabajo, el amor, la religión, el sexo y todo lo demás-y se le priva de toda esperanza de replegarse sobre un paisaje social más familiar, los trastornos que sufrirá serán dos veces más graves. Todavía más; si esta nueva cultura está a su vez en camino de un hervidero perpetúo y : si -peor aún- sus valores están sometidos a transformaciones incesantes; su sentimiento de extranjeridad no hará más que acrecentarse. Si no dispone más que de escasas señales para adoptar un comportamiento racional en el entorno radicalmente nuevo que es el suyo, puede llegar con facilidad a ponerse él mismo en peligro y a los otros con él". La conclusión a que llega Toffler es semejante a la de Rof: "Comprendemos mejor los sintomas sorprendentes de la crisis compleja que hace estragos a nuestro alrededor: el uso, cada vez más extendiào de las drogas, la inflación del misticismo, las explosiones periódicas de vandalismo y de violencia incontrolada, la política de nihilismo y la nostalgia de la apatia nociva de millones de individuos" 5 .

Las causas del mal son múltiples y entre ellas suelen mencionarse la superestimulación, el bombardeo de los sentidos, la sobreabundancia informativa, etc., etc, cuya consecuencia es el stress decisional, esto es, la incapacidad de tomar decisiones, para poder usar con libertad to que parecía ser el anhelo supremo prometido como felicidad en el reposo de la cosa adquirida. La sociedad actual no ha tenido en cuenta las limitaciones del ser humano, su agotabilidad. Primero le ha convertido en un ser capaz de consumir y para ello le obliga a ser una máquina productora; incitándole luego a poseer cuanto produce: producción, propaganda y consumo constituyen una marcha en espiral irrompible; sin posibilidad de pararse; sobre la que se asienta la economia del mundo. Es preciso desarrollar el deseo de tenerlo todo, de apetecerlo todo, sin reparar en que toda elección lleva aneja una gran carga de renuncias. Desde el clásico "burro de Buridán", a las reflexiones sobre la libertad de Sartre, se ha venido a demostrar que el exceso de ofertas $y$ posibilidades, en lugar de satisfacer los apetitos, son causa de angustia, indecisión y desencanto, porque se sufre más por aquello a lo cual ha de renunciarse que por el goce de lo adquirido.

Pasemos ya a lo que constituye el tema central de nuestro quehacer, a la figura y tarea del sacerdote ante un mundo así conmo-

5. A. TOFFLER, Le choc du futur (Paris 1971) 16, 125, 349. 
vido. ¿Cú́l es su papel?, ¿qué puede $y$, por lo tanto; qué debe : hacer? Para hallar una respuesta, podemos acudir a tres fuentes la primera es la intención de Dios que le eligió como su delegado ante los hombres; la segunda la de la Iglesia al encomendarle tareas definidas y carle orientaciones concretas; la tercera la de los hombres a. quienes es enviado.

En lo que a Dios respecta, se pueden aplicar a cada sacerdote, puesto que es alier Christus, las palabras de la Epístola a los hebreos: "Todo sumo sacerdote se escoge siempre entre los hombres y se le establece para que los represente ante Dios y ofrezca dones y sacrificios por los pecados" "La palabra Pontifex de la traducción latina es muy significativa; viene de puente, es decir, de comunicación entre dos orillas sobre el rio que separa el mundo transitorio de lo terreno del de la eternidad. Por él pueden pasar hombres y mercancias de un lado al otro: lo terreno para hacerse espiritual, esto para convertirse en realidades históricas. Si los puentes tuviesen capacidad de razonar y libertad para elegir, se encontrarian tentados a renunciar a su papel de unir extremos de tan difícil coordinación. O bien lo temporal atrae lo eterno para ponerlo a su servicio; o se siente tan subyugada por lo eterno que olvida la realidad transitoria con sus inexcusables exigencias. Esta contradicción entrañada profundamente en su misión, el sacerdote la percibe en sí mismo como los demás hombres; por ser cuerpo y alma o, si se quiere en un sentido más agustiniano, cuerpo, alma y espiritu, lleva en su interior la tensión siempre insatisfecha de la doble tendencia, incrementada al tomar sobre sí el problema de los otros para quienes está elegido como representante de ellos ante Dios y de Dios ante los hombres.

Cuanto Cristo exigió y prometió a sus apóstoles ha de tomarlo cada sacerdote como dicho para él. ¿Qué les manda decir, como primer saludo, cuando les envía a predicar en su nombre? "Al entrar en una casa saludadies con la paz. Si la casa se lo merece, la paz que deseśis se posará sobre ella; si no se la merece, vuestra paz volverá a vosotros". La paz; precisamente lo que más necesita el hombre de hoy; lo que está anhelando sentir en su alma atormentada. Ahora bien; a poco que consideremos lo que es la paz, sobre todo una paz con posibilidades de difusión, encontramos una exigencia superior a las fuerzas humanas. Nadie puede llevar la paz, si no la tiene en su propia alma, si no está por encima de cuanto separa a

6. Hebr 5,1.

7. $M t \quad 10,12$. 
unos hombres de otros, sea la situación económica, las ideologías políticas y sociales, las simpatías o antipatías personales. Al sacerdote se le prohibe "tomar partido" por las cuestiones humanas, ha de "hacerse indiferente" como pedia san Ignacio, lo cual no es 10 mismo que mirar las cosas con indiferencia. El no puede apasionarse por nada, y ser, en cambio, capaz de apasionarse por cada uno de los hombres, hacerse uno de ellos. Así lo entendía Pablo, al escribir: "Siendo libre respecto a todos, me hice esclavo de todos para ganar al mayor número posible. Con los judíos me hice como judio, para ganar judios; con los súbditos de la ley, me hice como súbdito de la ley - yo que no lo soy-, para ganar a los súbditos de la ley. Con los que están sin ley, me hice como el que está sin ley - yo que no estoy sin la ley de Dios, sino que estoy con la ley de Cristo-, para ganar a los que están sin la ley. Con los débiles me hice débil, para ganar a los débiles. Me hice todo para todos, para salvar a algunos a toda costa. $\mathrm{Y}$ todo esto lo hago por el evangelio, para tener parte en él" ${ }^{8}$.

Traducido esto a nuestra situación actual tendriamos que decir: con los de derechas me hice de derechas, con los de izquierdas de izquierdas; racista con los racistas y antirracista con sus contrarios, etc., etc. Dicho así parecería una recomendación de hacerse "chaquetero" o dispuesto a ponerse al servicio del más poderoso en cada momento para evitarse dificultades. Todos sabemos que no se trata de tal cosa, porque lo que justifica y exige ese plurimorfismo proteico es el Evangelio, que obliga a transcender los partidismos terrenos, a fin de buscar en los hombre lo que nunca debe estar comprometido con las opciones temporales, porque pertenece a Dios, y para El, todos los hombres tienen una posibilidad de salvación.

Siguiendo esta línea, ¿no caeremos en el riesgo de apartarnos de los problemas que interesan y apasionan a los hombres y que desean ver al sacerdote a su lado, a fin de legitimar así sus teorías y aspiraciones? En el Evangelio no encontramos apoyo para justificar algún modo de "compromiso" temporal, pero sí hay algo que indica hacia quiénes se inclinó Jesús, poniéndolo como signo de su mesianidad. Al enviar Juan el Bautista a sus discípulos para preguntarles si era él quien habia de venir, respondió: "Id a contarle a Juan lo que estáis viendo y oyendo: Los ciegos ven y los cojos andan, los leprosos quedan limpios y los sordos oyen, los muertos resucitan y a los pobres se les anuncia la buena noticia" ? Los inválidos, los enfer-

8. 1 Cor 9, 19-25.

9. $M t 11,15$. 
mos, los pobres son quienes han de tener la preferencia del que a Cristo representa. ¿Supone esto que los no incluidos en la desgracia y el dolor han de ser abandonados? De ningún modo; pero el primer puesto corresponde a los desheredados de este mundo, porque su atención seguirá siempre siendo la marca del verdadero seguidor del Maestro.

Si buscamos la respuesta de nuestra pregunta en las orientaciones de la Iglesia, encontramos la misma doctrina de Cristo, actualizada en cada momento de la Historia. En el Vaticano II se dice: "Por su vocación y ordenación, los presbíteros de la Nueva Alianza son en cierta manera separados en el seno del pueblo de Dios, no para que se alejen de él, ni de cualquier hombre, sino para que puedan consagrarse totalmente a la obra que el Señor los llamó. No podrán ser ministros si no fueran testigos y dispensadores de otra vida que la terrena; pero tampoco podrían prestarles su ayuda si se sintieran extraños a su existencia y condiciones. Su mismo ministerio les exige, por singular título, que no se conformen en nada a este mundo; y al mismo tiempo requiere que vivan en este mundo, en medio de los hombres, y que como buenos pastores conozcan a sus ovejas e intenten atraer aún a aquéllas que no son todavía de este redil, para que también ellas oigan la voz de Cristo y se forme un solo rebaño bajo un solo pastor. Mucho ayudan a conseguir esta finalidad aquellas virtudes que con razón se estiman en la sociedad humana; como la bondad, la sinceridad, la fortaleza de alma, la constancia, la asidua preocupación por la justicia, la urbanidad y otras cualidades que recomienda el Apóstol Pablo cuando escribe: "Pensad en cuanto hay de verdadero, de puro, de justo, de santo, de amable, de laudable, de virtuoso, de digno de alabanza" (Flp. 4,8)... La predicación sacerdotal, muy difícil con frecuencia en la coyuntura actual del mundo, para mover mejor las mentes de los oyentes, ha de exponer la palabra de Dios no sólo de manera general y abstracta, sino que ha de adaptar la verdad eterna del Evangelio a las circunstancias concretas de la vida ${ }^{10}$.

El reconocimiento de la dificultad de este consejo no depende sólo del sacerdote; en gran parte proviene de quienes escuchan su palabra. "Va a llegar el momento, escribe Pablo a Timoteo, en que la gente no soportará la doctrina sana; no, según sus propios caprichos, se rodearán de maestros que les halaguen el oído; se harán sordos a la verdad y darán oídos a las fábulas" "

10. Praesbiterorum Ordinis, núms. 3-4.

11. 2 Tim 4,3 . 
cerdotes, en cumplimiento de esta advertencia, aplican la palabra de Dios, como hierro candente a su auditorio, son tachados de comunistas y perturbadores, si predican contra la injusticia social a unos, $y$ de capitalistas $y$ vendidos al dinero y al poder, si 10 hacen otros. Así se convierten algunos, cambiando la dirección evangélica en "halagadores de los oídos" de quienes les escuchan. Claudican, ciertamente, pero ¿no son culpables también quienes, en lugar de buscar la verdad de Cristo, que redimiría sus almas de los lazos que les atan esclavizándoles a este mundo, esperan palabras y sentencias justificadoras de sus defectos y afanes egoístas? Una gran parte de la literatura anticlerical ha surgido de este abandono de la línea recta y severa que Dios nos pide. $Y$ ciertamente, un gran número de esos libros podrian servir de lectura espiritual revulsiva para muchos. Si así se hubiera hecho es probable que nos sentiríamos culpables cel "gran escándalo de nuestro siglo: la pérdida de las masas obreras para la Iglesia”, como denunció Pio XI.

Preguntemos, por último, a los seglares. En 1960, euando comenzaba el Concilio Vaticano II, se publicó una encuesta cuyas dos preguntas enan: "¿Cómo ve Vd, al sacerdote?, ¿nué espera de êl?". Contestaron treinta y uno, todos muy conocidos en su mayor parte seglares Lo que entonces respondieron constituye un programa con plena validez hoy; porque miraban a un ideal, y los ideales nunca pasan, siempre están delante y sólo se alejan cuando pensamos haberlos alcanzacio. Tomemos al azar algunas opiniones: "Así veo al sacerdote: en su naturaleza de hombre, pero con su condición superior, que nos trasmite la fe, incluso en aquellos momeritos en los que, de su postura, parecería derivarse un peligro para vacilar en ella. Del sacerdote espero dedicación apasionada al ideal por él escogido; perfección humana a cubierto de la minima sospecha; abertura y combrensión sumas para los problemas de los demás y: desprecio para los problemas propios; generosidad sin límites, entrega sin reservas, manifestación permanente de la caridad, valentía para enfrentarse con los engaños y para combatir las injusticias, independencia frente a todo intento, descarado $u$ oculto, de enfeudamiento alejamiento de todo interés politico, social o económico, para poder gritar siempre la apasionante pureza de la verdad; acercamiento a la juventud, porque lo necesita, y a los pobres y desgraciacos, porque nadie les protege y todos estamos dispuestos a especular con el "slogam" de su tutela; alegria sobrenatural y competencia técnica humana" ${ }^{12}$. Esto dice Manuel Alon García, catedrá-

12. Cómo ve usted el sacerdote? (Salamanca 1970) 32-34. 
tico en Barcelona; y con ello se podría escribir todo un tratado de formación sacerdotal.

José L. Aranguren pedía: "La actitud propia del sacerdote no es política o político-social. Es verdad. Pero desde ella tiene que enfrentarse con el mundo y juzgarle. En esto el sacerdote tiene que parecerse al intelectual... esperamos que sea santo (aunque nunca llegue a ser elevado a los altares) y que, siéndolo, nos ayude a serlo nosotros también. $O$, cuando menos, a ser menos pecadores. Para ser santo, es decir, verdaderamente de Dios, tendrá que ser verdadero y veraz, oportune et importune. (Lo que no es sinónimo de ser revolucionario). $Y$ tendrá que hablar de Dios con conocimiento y amor, es decir, tendrá que ser teólogo. (Aunque no llegue nunca a escribir tratados de teología). Santidad y apostolado, teología y no-conformismo" ${ }^{13}$.

Según Miguel Delibes, "la propaganda pro-seminario suele centrarse en frases como ésta: "Todos deseamos un sacerdote a nuestro lado a la hora de la muerte". Esto es plausible siquiera no deje de ser una interpretación egoísta de la misión del sacerdote en el mundo. Yo preferiría que la propaganda en favor del Seminario se orientase asi: "Todos necesitamos un sacerdote a nuestro lado a la hora de la vida". Y esto es lo que no fue ayer el sacerdote y lo que, afortunadamente, empieza a ser - creo yo- en nuestro tiempo... En nuestro tiempo no cabe la espera; hay que tener ese sexto sentido de la anticipación, salir al encuentro de la vida y ganarle al enemigo por la mano" ${ }^{14}$.

D. Gregorio Marañón, ya en las postrimerias de su vida, pero con la profundidad y sabiduría acumuladas en ella, da una respuesta, en las pocas líneas que envió, digna de ser meditada, por lo que deja en el aire, para que el discreto lector saque la consecuencia: "Yo veo a los sacerdotes jóvenes con un absoluto optimismo y espero mucho de ellos, todo lo que supone la grave situación de las conciencias españolas. Pero déjeme con esta sola afirmación. Si añadiera algo a esto tan consolador, tendria que ser sombrío y pesimista, y estoy cecidido a no contribuir al entenebrecimiento de nadie, ni siquiera con la insignificante opinión mia" ${ }^{15}$.

Creo que no es necesario seguir acumulando datos; en estos pocos espigados al azar se encuentran las caracteristicas suficientes

13. Cómo ve usted al sacedote?, 53-55.

14. Cómo ve usted al sacerdote?, 108-109.

15. Cómo ve usted al sacerdote?, 210. 
para dar respuesta a nuestro tema cuyo resumen servirá para cerrarlo.

Lo primero que aparece como nota común en las tres fuentes elegidas para buscar respuesta a los primeros interrogantes que planteábamos es la exigencia y el deseo de que el sacerdote sea un "hombre de Dios; es decir, que su vida y su espíritu estén impregnados de la espiritualidad que ha de comunicar a los demás. Si "ha sido tomado entre los hombres", no fue elegido por Dios para aislarlo en soledad incomunicada, sino que "le ha constituido para ellos"; los hombres tienen un derecho sobre él y pueden recurrir a su ayuda, para que les guíe a conseguir su salvación. No le pedirán solución para sus problemas temporales, sino luz y alientos para resolver los eternos.

Esta misión no podrá realizarla bien sin establecer un diálogo con los hombres. Aquí aparece el segundo rasgo: para cumplir bien su cometido es preciso que los hombres le entiendan. $Y$ no entenderán su lenguaje y el contenido del mismo si no se sumerge en la condición humana y en las situaciones en las que ellos están envueltos. Hablarle en términos desconectados de la realidad significa imposibilitar el diálogo fecundo. Si es hombre como los demás, sometido a situaciones equivalentes a los demás y siente iguales anhelos $\mathrm{y}$ padece idénticas debilidades, ha de asemejarse a su Maestro, que se hizo hombre para mejor comprender a los hombres: "No tenemos un sumo sacerdote incapaz de compadecerse de nuestras flaquezas, sino uno probado en todo igual que nosotros, excluido el pecado" ${ }^{16}$.

Unidos estos dos rasgos dan una fórmula perfecta. Puesto que vivimos en un mundo en transformación, cualquier forma de instalación en lo transitorio, nos alejará de la realidad. Es preciso navegar en plena corriente, sin pararse a reposar en la orilla. De lo contrario, los hombres, arrastrados por los rápidos del río de la vida, perderán el contacto con nosotros y nosotros con ellos.

Lo que cambia en la vida y pasa con las modas o situaciones históricas no es lo esencial de la vida de cada hombre ni del destino de la humanidad. Hay algo en ella permanente, invariable, constante y definitivo: es lo que de eterno hay en cada hombre. La gran tragedia de las épocas de transición histórica - y la actual lo es en tanta o mayor medida que lo fueron la caída del imperio romano y el Renacimiento - es el olvido de lo permanente y esencial, por causa de la preocupación exclusiva de las novedades y riesgos o por la ilusión esperanzada en lo efímero. ¿Qué hacen los hombres apega-

16. Hebr 4,15 . 
dos a sus riquezas en los tiempos de inseguridad económica? Dejan de invertirlos en bienes inestables y compran oro, joyas, tierras, obras de arte. Saben que estos valores son siempre firmes y no están sometidos a los vaivenes de la Bolsa ni les alcanzan las depreciaciones de las divisas. La humanidad actual está perdiendo el sentido del valor de la vida, de la paz interior, de la estabilidad del alma. En lugar de buscar los bienes inconmovibles, quiere apoyarse en lo que si vale hoy, mañana será despreciado; gasta sus energias en satisfacciones y placeres que, precisamente por buscar en ellos lo que no pueden ni nunca podrán dar, la paz interior, dejan como regusto la insatisfacción, el hastio y a veces, al final la desesperación.

Son por eso estos períodos los más propicios para llamar a grandes voces a quienes buscan lo que no encuentran, algo que muchos no saben lo que es, pero lo intuyen, sin reconocerlo en las formas clásicas y tradicionales de la religiosidad de sus padres y abuelos. ¿Por qué se va a buscar en ritos de religiones orientales una mística, teniendo a la mano otra mucho más rica, sensata y segura? Jesús lo dijo: "Venid a mí todos cuantos estáis rendidos y abrumados; yo os consolaré. Cargad mi yugo y aprended de mi que soy manso y humilde de corazón: encontraréis vuestro respiro, pues mi yugo es llevadero y mi carga ligera" ${ }^{17}$.

No nos quieren políticos, no nos piden que les enseñemos técnicas; no esperan de nosotros que resolvamos sus cuestiones profesionales, sociales, familiares. Quieren que, en nombre de Dios, les hagamos ver claro, que les acerquemos a Jesús para ser iluminados. Rechazan el paternalismo, pero quieren ver en nosotros al hermano y al amigo, al guía que les muestre el camino de la luz. "Es la persona del hombre la que hay que salvar. Es la sociedad humana la que hay que renovar", ha dicho con frase espléndida y certera el Concilio ${ }^{18}$. La salvación de cada persona humana es cosa de Dios, pero somos los sacerdotes sus instrumentos. La renovación de la sociedad nos compete de manera indirecta, como colaboradores de los seglares. Es posible que la sociedad no quiera renovarse, o no pueda, pero no por ello deja de ser posible la salvación de los hombres.

Visto el panorama del mundo, no se percibe, en ninguno de los bandos en que se halla dividido, grandes posibilidades de cambio favorable. Los problemas sociales y económicos, los de la cultura, la alimentación y la paz no despiertan sino intentos tan materialistas como las causas que los producen. Devaluaciones de monedas, im-

17. $M t \quad 11,29$.

18. Gaudium et spes, núm. 3 . 
puestos, planes de desarrollo, crecimiento de la producción; todo esto no rebasa el nivel de lo material, donde no tiene cabida el espiritu, por cuya ausencia han venido todos los males. Las colectividades, como los particulares, se hallan cercados por un círculo vicioso sin fuerzas ni verdaderos deseos de salir de él; están ciegos para no ver el remedio, que sólo puede hallarse en tomar en serio el Evangelio de Cristo. "Yo soy la luz del mundo: el que me sigue no anda en tinieblas, tendrá la luz de la vida" ${ }^{19}$. Luego todo aquel que no le sigue andará en tinieblas. ¿No parece que el mundo actual está invadido de la noche del vicio, de la violencia y de la desesperanza?

El sacerdote, en este mundo en transformación, debe ser un despertador de esperanza, no sólo de la suya, sino, como escribió $\mathrm{Pe}-$ dro Laín. "el sacerdote debe especializarse, valga la expresión, en el cumplimiento del imperativo del amor que santo Tomás llama "esperar para otro"... Pero la esperanza - también lo enseñó santo Tomás- es hábito distinto del mero deseo, y exige el cumplimiento de acciones esforzadas y generosas. Sin magnanimidad no hay verdadera esperanza. ¿Cómo, entonces, ese "esperar para otro" đel sacerdote habrá de expresarse operativamente en el mundo actual? $\mathrm{He}$ aqui una pregunta cuya respuesta exige a la vez caridad, osadía e imaginación. La pregunta que yo, hombre del siglo, pobre hombre menesteroso de que esperen por mí, haría estampar en la aulas de todos los seminarios de España" ${ }^{20}$.

Esto es lo que los hombres esperan de nosotros; esta es la respuesta que debemos darles; esto es lo que puede salvar a un mundo que camina hacia la noche del caos del cual sólo el Espíritu del Señor será capaz de sacarlo de nuevo, en una renovada creación.

CÉSAR VACA, OSA.

MADRID

19. Jn 8,12 .

20. Encuesta citada 190. 